\author{
Christopher McTiernan MD, \\ Bjørn Haagenvik MD
}

\title{
Strümpell's disease in a patient presenting for Cesarean section
}

Purpose: The anesthetic management of a parturient with Strümpell's disease (hereditary or familial spastic paraparesis) who presented for Cesarean section is described. This neurological disorder is briefly reviewed and anesthetic implications of the condition are discussed.

Clinical Features: A 30-yr-old woman in premature labour presented for Cesarean section. She had bilateral lower limb spastic paresis which had resulted in her being confined to a wheelchair from the age of I 3 yr. A diagnosis of Strümpell's disease had been made in childhood. She was currently receiving thromboprophylaxis, having suffered a deep venous thrombosis four weeks after a previous Cesarean section. The patient was in mild respiratory distress. Despite a history of uneventful general anesthesia and the aforementioned complicating factors, epidural anesthesia was considered the most appropriate technique in these circumstances. An epidura catheter was sited at the $L_{3} L_{4}$ interspace. Adequate anesthesia for the procedure was obtained after administration of $20 \mathrm{ml}$ lidocaine $2 \%$ with $100 \mu \mathrm{g}$ epinephrine and $100 \mu \mathrm{g}$ fentanyl in saline. Postoperatively and at six month follow-up there were no neurological complications related to the use of epidural anesthesia.

Conclusion: Strümpell's disease is an inherited progressive spastic paresis predominantly affecting the lower extremities. Epidural anesthesia appears to be an appropriate technique when administering anesthesia for Cesarean section under similar circumstances.

Objectif : Décrire la gestion de l'anesthésie d'une parturiente atteinte de paralysie spinale spasmodique (paraparésie spastique familiale ou héréditaire) admise pour une césarienne. Revoir brièvement ce désordre neurologique et discuter des implications anesthésiques liées à cet état.

Eléments cliniques : Une fernme de 30 ans, en travail prématuré, s'est présentée pour subir une césarienne. Elle avait une parésie bilatérale des membres inférieurs qui l'avait confinée à un fauteuil roulant depuis l'âge de 13 ans. Pendant son enfance, un diagnostic de paralysie spinale spasmodique avait été fait. Au moment de son admission, elle recevait une thromboprophylaxie, car elle avait souffert d'une thrombose veineuse profonde quatre semaines après une précédente césarienne. La patiente présentait une légère détresse respiratoire. Malgré une anesthésie générale déjà administrée avec succès et les facteurs de complications susmentionnés, l'anesthésie péridurale a été considérée comme la technique la plus appropriée dans les circonstances. Un cathéter épidural a été placé dans l'espace entre $L_{3 .} L_{4}$. Une anesthésie adéquate a été obtenue à la suite de l'administration de 20 $\mathrm{ml}$ de lidocaine $2 \%$ et de $100 \mu \mathrm{g}$ d'épinéphrine et de $100 \mu \mathrm{g}$ de fentanyl dans une solution salée. Après l'opération et lors d'une visite de contrôle six mois plus tard, il n'y avait pas de complications neurologiques liées à l'usage de l'anesthésie péridurale.

Conclusion : La paralysie spinale spasmodique est une parésie héréditaire spastique et progressive affectant surtout les extrémités inférieures. L'anesthésie péridurale est apparue comme une technique appropriée à la césarienne dans des circonstances semblables.

From the Department of Anesthesiology and Intensive Care, Haugesund General Hospital, 5500 Haugesund, Norway. Address correspondence to: Dr. Christopher McTiernan, Phone: 47-52732000; Fax: 47-52732002;

E-mail: Christopher.McTiernan@FIH.RFK-HELSE.telemax.no Accepted for publication April 1, 1999. 
W E report the anesthetic management of a patient with Strümpell's disease who presented in premature labour and was delivered by Cesarean section. Strümpell's disease is a genetically determined neurodegenerative disorder. Patients suffer from spastic paresis predominantly of the lower limbs but may have multiple neurological deficits. Epidural anesthesia was considered the safest course of management for this patient. Alternative management strategies are discussed.

\section{Case Report}

A 30-yr-old woman with spastic paraparesis presented for emergency Cesarean section. This was her second pregnancy and she weighed $65 \mathrm{~kg}$. An elective Cesarean section had originally been planned but the patient went into premature labour at $36 \mathrm{wk}$ gestation.From the age of $16 \mathrm{mo}$, the patient had suffered from a progressive spastic paraparesis which resulted in her being confined to a wheelchair by $13 \mathrm{yr}$ of age. One brother was also affected by spastic paraparesis while she had two healthy unaffected siblings. Her condition had been diagnosed as Strümpell's disease (hereditary or familial spastic paraparesis) displaying an autosomal recessive mode of inheritance.

The patient had been hospitalized on numerous occasions with pneumonia, recurrent urinary infections and recurrent abdominal pain. Five years earlier the patient had undergone Cesarean section under general anesthesia after an uncomplicated pregnancy. She had on that occasion received succinylcholine, without incident. Four weeks after the operation she suffered an iliac vein thrombosis. This complication resulted in her receiving prophylactic low molecular weight heparin (5000 i.u. dalteparin $s c$ daily) during the present pregnancy until 33 wk gestation. Her medication was then changed to $60 \mathrm{mg}$ enoxaparin $s c$ daily until the time of surgery.

She smoked daily and reported increasing cough and sputum production in the days prior to her hospital admission. There was no history of cardiac disease. Sixteen hours had elapsed since enoxaparin was last administered. Physical examination revealed an anxious lady in active labour. Her temperature was normal but she was in mild respiratory distress. She was, however, capable of lying flat without worsening of her symptoms. Her ability to cough and clear secretions was limited by poor respiratory muscle function. Auscultation revealed coarse crepitations over both lungs fields. There was pronounced spasticity and paresis in both lower extremities but tactile sensory function was intact. Motor function in the upper extremities was minimally reduced while sensory function was preserved.
As the patient was in premature labour it was decided that Cesarean section should be performed without delay. General anesthesia was dismissed as an option as the patient expressed a desire to remain awake during the procedure. Additionally, general anesthesia would have required a rapid sequence induction and intubation due to the risk of aspiration. We regarded the use of succinylcholine as contraindicated due to the possibility of inducing hyperkalemia. We were also concerned that increased doses of non-depolarizing muscle relaxants would result in the need for prolonged postoperative ventilation with the inherent risk of pulmonary infection.

Regional anesthesia was considered the most appropriate course of management for this patient despite her neurologial condition and use of thromboprophylaxis. An epidural catheter technique with careful titration of local anesthetic was, in our opinion, preferable to spinal anesthesia. This allowed a more controlled rise in the level of the anesthetic block and the ability to preserve as much respiratory muscle function as possible. The patient accepted our plan for anesthetic management and was transported to the operating theatre.

The patient received $30 \mathrm{ml}$ sodium citrate solution po. Heart rate, non-invasive blood pressure and oxygen saturation were monitored. She received supplemental oxygen via a nasal catheter and was prehydrated with $500 \mathrm{ml}$ crystalloid. The patient was placed in the sitting position and prepared for anesthesia. An 18-guage Tuohy needle was inserted through a midline puncture at the $\mathrm{L}_{3-4}$ interspace and the epidural space identified by loss of resistance to saline. No difficulties were encountered in locating the epidural space or with insertion of the catheter. There were no parasthesia and an aspiration test revealed no evidence of cerebrospinal fluid or blood. A solution of $20 \mathrm{ml}$ lidocaine $2 \%$ containing $100 \mu \mathrm{g}$ epinephrine was prepared and $3 \mathrm{ml}$ were administered as a test-dose. Thereafter, incremental doses of the same solution were injected through the catheter. The patient received $20 \mathrm{ml}$ of this solution (including the test-dose) and $100 \mu \mathrm{g}$ fentanyl diluted in $6 \mathrm{ml} \mathrm{NaCl} 0.9 \%$ over ten minutes. When the upper level of anesthesia had reached the $\mathrm{T}_{5}$ level, Cesarean section was performed. The patient was hemodynamically stable during the procedure and her respiratory status remained unchanged. Total blood loss was estimated to be $300 \mathrm{ml}$. Delivery of a male infant was uncomplicated. Apgar scores were 9 at one and five minutes and he weighed $2,520 \mathrm{~g}$. He was noted to have a cleft lip and palate but was otherwise apparently healthy.

Postoperatively the patient was monitored closely for $24 \mathrm{hr}$. Sensation and motor power in the lower extrem- 
ities returned to preanesthetic levels within the expected time-frame for lidocaine. The epidural catheter was removed on the evening of the operation and two hours before the next scheduled dose of enoxaparin. The immediate postoperative period was uneventful. Some days later she became febrile and was subsequently treated for a left-sided pneumonia. Six months later, her neurological status was unchanged.

\section{Discussion}

Stümpell's disease is a rare neurological disease which was originally described in $1880 .^{1}$ It is also referred to as hereditary or familial spastic paraparesis. ${ }^{2-5}$ This is a genetically determined neurodegenerative disorder in which the signs and symtoms are predominant in the legs. ${ }^{2}$ The existence of "pure" and "complicated" forms of the disease, based on the clinical manifestations, has been the subject of much controversy in the literature. $^{3-5}$ "Pure" forms of the disease display predominantly motor impairment, late onset of symtoms, autosomal dominant mode of inheritance and slow progression of paresis. ${ }^{4-5}$ "Complicated" forms of the disease show variable or early onset and progression of symtoms, differing modes of inheritance (dominant or recessive) and commonly sensory deficits. ${ }^{2,3,5}$ Multisystemic subclinical involvement of the CNS has been demonstrated in "pure" forms of the disease. ${ }^{3}$ Neuropathological study has revealed degenerative changes of the corticospinal tracts decreasing from lower lumbar to cervical level and of the posterior columns increasing from lumbar to upper cervical level as well as degeneration of the spinocerebellar tracts in approximately $50 \%$ of patients. ${ }^{2}$

We were unable to find any reports on the anesthetic management of patients with Strümpell's disease, presenting for emergency surgery. The administration of succinylcholine is known to be hazardous in patients with paraplegia due to the risk of inducing hyperkalemia. The hyperkalemic response may be apparent as early as three-seven days after denervation but the duration of risk in non-progressive neurological disease is less certain. ${ }^{6}$ It has also been observed in the weeks following transient episodes of paraparesis and paraplegia. ${ }^{7,8}$ In conditions of progressive paraparesis this risk may be continually present and it would appear advisable to avoid the use of succinylcholine. The absence of any clinical adverse effect to a previously administered dose of succinylcholine should not be interpreted as a guarantee of its safety. ${ }^{6}$

Patients presenting for Cesarean section are at risk of aspiration during induction of general anesthesia. Increased doses of non-depolarizing muscle relaxants allow rapid tracheal intubation and may be used in sit- uations where succinylcholine is contraindicated..$^{9,10}$ When rapid tracheal intubation is mandatory, 0.9-1.2 $\mathrm{mg} \cdot \mathrm{kg}^{-1}$ rocuronium seems an appropriate choice of non-depolarizing agent. Its onset time is comparable with that of succinylcholine and the mean duration of action in normal patients has been shown to be 53-73 min. ${ }^{10}$ Patients with spastic paraparesis, however, appear to be hypersensitive to non-depolarizing muscle relaxants, ${ }^{11}$ and possibly normal or slightly increased doses may be sufficient for intubation. Careful neuromuscular monitoring should be employed. Prolonged mechanical ventilation may be required postoperatively and increases the risk of pulmonary infection. Awake intubation should be considered if this is acceptable to the patient and sufficient time is available.

The use of regional anesthesia has generally been discouraged in patients with central nervous system disease due to the theoretical risk of exacerbating the disease process. ${ }^{12,13}$ There is no evidence that this is the case. The potential risks of general anesthesia to the parturient are widely acknowledged, ${ }^{14}$ such that the anesthesiologist should strongly consider employing regional anesthesia for these patients despite the presence of preexisting neurological disease. Regional anesthesia and analgesia is being increasingly used in patients with preexisting neurological disease and particularly in obstetric anesthesia. Reports on the use of regional anesthesia in patients with multiple sclerosis, ${ }^{15}$ syringomyelia, ${ }^{16}$ Friedreich's ataxia, ${ }^{17}$ neurofibromatosis, ${ }^{18}$ paraplegia, ${ }^{19}$ Isaac's syndrome, ${ }^{20}$ and amyotrophic lateral sclerosis, ${ }^{21}$ clearly demonstrate a change in our approach to the anesthetic management of these patients. There are, however, no controlled studies to support the use of regional anesthesia in patients with chronic neurologi$\mathrm{cal}$ disease. It is, therefore, important that these patients be thoroughly informed about recommendations regarding their care.

Patients with neurological disease commonly have poor respiratory muscle function with associated decreased respiratory reserve. In our opinion, epidural anesthesia with slow titration of local anesthesia affords a greater control over the final level of anesthetic blockade than single-shot spinal anesthesia. Preservation of as much respiratory muscle function as possible would appear advantageous in these patients. Furthermore, it has been suggested that epidural anesthesia may be safer than spinal anesthesia in patients with demyelinating disease. ${ }^{15}$ Local anesthetic concentrations in the white matter of the spinal cord are 3-4 times higher with spinal administration than with epidural administration $\left(1.37 \mu \mathrm{g} \cdot \mathrm{mg}^{-1}\right.$ ps 0.4 $\left.\mu \mathrm{g} \cdot \mathrm{mg}^{-1}\right) .{ }^{15}$ This fact, combined with concerns regard- 
ing the potential neurotoxicity of local anesthetics, would seem to favour the use of epidural anesthesia over spinal anesthesia, especially in the presence of preexisting neuronal damage. There is however, no convincing evidence to support this conclusion.

The safety of regional anesthesia in patients using low-molecular weight heparin has recently received much attention..$^{22,23} \mathrm{It}$ is feared that the combination increases the risk of epidural and spinal hematoma. Practice guidelines have been published recommending that regional anesthesia be delayed for 10-12 hr after the last administration of low-molecular weight heparin. ${ }^{22,23}$ Epidural hematoma has recently been associated with epidural anesthesia and the use of 30 $\mathrm{mg}$ enoxaparin $s c$ twice daily. ${ }^{24}$ What dosage, if any, that can be safely used in association with regional anesthesia seems unclear. It would be prudent to avoid regional anesthesia when the patient is using dosages other than those recommended for thromboprophylaxis and when the risks of general anesthesia are considered relatively minor.

In summary, we report the successful use of epidural anesthesia in a patient with Strümpell's disease who presented for Cesarean section. This hereditary neurodegenerative disease causes spastic paraparesis with variable sensory deficits. General anesthesia is potentially hazardous in these patients and regional anesthesia would be advisable under similar circumstances. We suggest that epidural anesthesia has theoretical advantages over spinal anesthesia and may be the technique of choice.

\section{References}

1 Strümpell A. Beitrage zur Pathologie des Ruckenmarks. Arch. Psychiatr Nervenkrankheiten 1880; 10: 217-38.

2 Bruyn RPM. The neuropathology of hereditary spastic paraparesis. Clin Neurol Neurosurg 1992; 94: S16-8.

3 Tedeschi G, Allocca S, Di Costanza A, et al. Multisystem involvment of the central nervous system in Strümpell's disease. A neurophysiological and neuropsychological study. J Neurol Sci 1991; 103: 55-60.

4 Scheltens P, Bruyn RPM, Hazenberg GJ. A Dutch family with autosomal dominant pure spastic paraparesis (Strümpell's disease). Acta Neurol Scand 1990; 82: 169-73.

5 Holmes GL, Shaywitz BA. Strümpell's pure familial spastic paraplegia; case study and review of the literature. J Neurol Neurosurg Psychiatry 1977; 40: 1003-8.

6 Martyn JAJ, White DA, Gronert GA, Jaffe RS, Ward $J M$. Up-and-down regulation of skeletal muscle acetylcholine receptors. Effects on neuromuscular blockers. Anesthesiology 1992; 76: 822-43.
7 Feldman JM. Cardiac arrest after succinylcholine administration in a pregnant patient recovered from GuillainBarré syndrome. Anesthesiology 1990; 72: 942-4.

8 Greenawalt JW III. Succinylcholine-induced hyperkalemia 8 weeks after a brief paraplegic episode. Anesth Analg 1992; 75: 294-5.

9 Koller $M-E, H$, Husby $P$. High-dose vecuronium may be an alternative to suxamethonium for rapid-sequence intubation. Acta Anaesthesiol Scand 1993; 37: 465-8.

10 Magorian T, Flannery KB, Millar RD. Comparison of rocuronium, succinylcholine and vecuronium for rapidsequence induction of anesthesia in adult patients. Anesthesiology 1993; 79: 913-8.

11 Brown JC, Charlton JE. Study of sensitivity to curare in certain neurological disorders using a regional technique. J Neurol Neurosurg Psychiatry 1975; 38: 34-45.

12 Kane RE. Neurologic deficits following epidural or spinal anesthesia. Anesth Analg 1981; 60: 150-61.

13 Jones RM, Healy TEJ. Anaesthesia and demyelinating disease. Anaesthesia 1980; 35: 879-84.

14 Muir HA. General anaesthesia for obstetrics: is it obselete? Can J Anaesth 1994; 41: R20-5.

15 Warren TM, Datta S, Ostheimer GW. Lumbar epidural anesthesia in a patient with multiple sclerosis. Anesth Analg 1982; 61: 1022-3.

16 Nel MR, Robson V, Robinson PN. Extradural anaesthesia for caesarean section in a patient with syringomyelia and Chiari type 1 anomaly. Br J Anaesth 1998; 80: 512-5.

17 Kubal K, Pasricha SK, Bhargava M. Spinal anesthesia in a patient with Friedreich's ataxia. Anesth Analg 1991; 72: 257-8.

18 Dounas M, Mercier FJ, Lhuissier C, Benbamou D. Epidural analgesia for labour in a parturient with neurofibromatosis. Can J Anaesth 1995; 42: 420-4.

19 Crosby E, St-Jean B, Reid D, Elliott RD. Obstetrical anaesthesia and analgesia in chronic spinal cordinjured women. Can J Anaesth 1992; 39: 487-94.

20 Morgan PJ. Peripartum management of a patient with Isaacs' syndrome. Can J Anaesth 1997; 44: 1174-7.

21 Kochi T, Oka T, Mizuguchi T. Epidural anesthesia for patients with amyotrophic lateral sclerosis. Anesth Analg 1989; 68: 410-2.

22 Horlocker TT, Heit JA. Low molecular weight heparin: biochemistry, pharmacology, perioperative prophylaxis regimens, guidelines for regional anesthetic management. Anesth Analg 1997; 85: 874-85.

23 Breivik $H$. Neurological complications in association with spinal and epidural analgesia - again. Acta Anaesthesiol Scand 1998; 42: 609-13.

24 Hynson JM, Katz JA, Bueff HU. Epidural hematoma associated with enoxaparin. Anesth Analg 1996; 82: 1072-5. 